\title{
Wind Turbine Concept for Educational Purposes
}

\author{
Ivica Lovrić \\ University of Split
}

\author{
Slobodanka Jelena Cvjetković \\ University of Split
}

\author{
Silvano Jenčić \\ University of Split \\ Ivan Papučić \\ University of Split
}

\begin{abstract}
The environmental awareness of modern society is changing regard to the use of electrical sources. Change of climatic conditions, as a consequence of fossil fuel energy use, increases the need for renewable energy research. Consequently, a wind turbine will be installed on the premises of the University Department of Professional Studies at the University of Split, for educational purposes. Based on an annual assessment of energy production and consumption a wind turbine project is developed. This paper explains the main concept of wind turbine operation. The system is controlled manually or remotely by programmable logic controller (PLC) and supervisory control and data acquisition (SCADA), with the possibility to measure and monitor all relevant points in the system. The purpose of this system is to be used to perform laboratory exercises and to educate students of the Department. It also describes the possibility of integrating the system into an internal electric power system.
\end{abstract}

Keywords: wind turbine, wind farm, renewable energy sources, power generation, SCADA

\section{INTRODUCTION}

This paper describes a wind turbine system that will be installed within the University Department of Professional Studies at the University of Split for the purpose of students' education. The first part of the paper gives general overview of wind energy, wind turbine system and the associated generator. Furthermore, the main components of the system, their sizing and installation are explained. Design of the system was based on annual assessment of energy production, consumption and storage.

Second part of the paper describes how the system can be controlled and monitored. It can be done manually (locally) via the control panel or automatically (remotely) via the PLC and SCADA system. The system is designed to enable measurements in all relevant points with the possibility of reading them on the 
measuring instruments and the computer. Monitoring and processing of measuring data will be also possible through the Internet.

In the last part, we present an overview of the laboratory exercises that will be performed on the system and the possibilities of integrating wind turbine system into the internal power system.

\section{WIND TURBINE OVERVIEW}

Wind speed is a fundamental parameter in order to design wind turbine. Before designing a wind turbine, it is necessary to determine the wind potential of the site due to the interdependence of the wind speed and produced electrical energy. Optimal data are obtained by measuring at a potential location using anemometers over a long period of time. In addition, wind data for a specific location issued by the State Meteorological Institute or software tools can be used to analyze the suitability of an area for the purpose of harnessing wind energy.

The conversion of wind kinetic energy into kinetic energy of shaft rotation is performed through the rotor blades and wind turbine. The optimum degree of aerodynamic conversion is the so-called Betz's limit, which equals 59.3\% (Karadža, et al., 2009). When converting energy, in addition to wind speed and air density, the surface described by the rotor blades and their shape should be considered. In practice, additional energy conversion losses are inevitable so modern wind turbines achieve maximum efficiency of $45-50 \%$. Maximum transformed power is determined by the following equation derived by Carl Betz:

$P_{t, \max }=0,593 * \frac{\rho * v^{3}}{2}$

where:

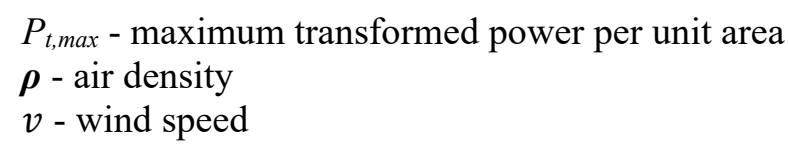

Due to the variable wind speed, the main considerations are based on the achieving maximum efficiency of wind turbine. The wind turbine generator can be driven at a constant or variable speed. With the development of power electronics, synchronous generators are used instead of asynchronous, which can be driven at variable speeds. This approach maximizes the use of wind energy.

Furthermore, with discovery of strong permanent magnets such as neodymium magnets (Neodymium Iron-Boron, $\mathrm{NdFeB}$ ), preference is given to synchronous generators with permanent magnets (Permanent Magnet Synchronous Generator, PMSG). These generators are extremely efficient, but their limitation is the constant excitement that cannot be controlled (Žarko, et al., 2017).

The structure of wind turbine based on synchronous generator with permanent magnets is shown in Figure 1. In a design like this, the generator is driven by direct drive without gearbox. This reduces mechanical transmission losses, which simplifies the device itself. On the generator side there is an inverter, which has the task of controlling the torque of the generator in order to maintain optimum power. The second converter controls the power supplied to the power grid. Braking of low-power wind turbines that charge batteries is often performed using a short circuit (Manwell, et al., 2009). 


\section{FIGURE 1}

\section{POWER GRID CONNECTION OF SYNCHRONOUS GENERATOR}

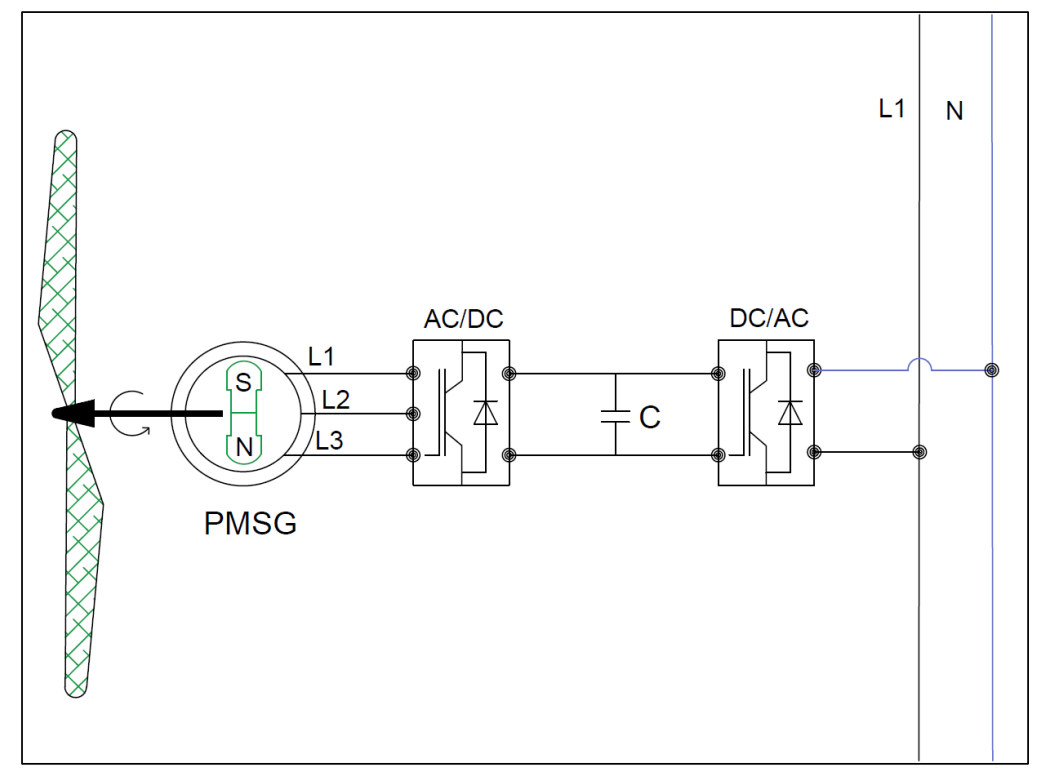

\section{WIND TURBINE DESIGN}

A wind turbine with a monitoring and control system will be installed at the University Department of Professional Studies at the University of Split. The system will be used for students' education and therefore will be primarily adapted for performing laboratory exercises with the possibility of its integration later into the internal electrical power system. The first step in design is based on the estimation of electrical energy consumption and production. Consumption shown in Table 1 refers to the system's and consumers' power supplies required to perform laboratory exercises.

TABLE 1

ESTIMATION OF ELECTRICAL ENERGY CONSUMPTION

\begin{tabular}{|l|c|c|c|c|}
\hline Consumer & Power $[\mathrm{W}]$ & Units & Hours [h] & Consumption [Wh/day] \\
\hline Consumer 1 & 50 & 1 & 1 & 50 \\
\hline Consumer 2 & 500 & 1 & 0,2 & 100 \\
\hline Consumer 3 & 20 & 1 & 24 & 480 \\
\hline \multicolumn{2}{|l|}{ Total Consumption } & & & 630 \\
\hline
\end{tabular}

Next step is to determine the wind potential of the location where the wind turbine will be mounted. Figure 2 shows a preview of the wind rose for the wider Split area, which shows the average wind speed and direction for December 2019. Daily wind speed for the specified area is shown in Figure 3 (Institute of Oceanography and Fisheries Web site, 2019). 
FIGURE 2

WIND ROSE - AREA OF SPLIT

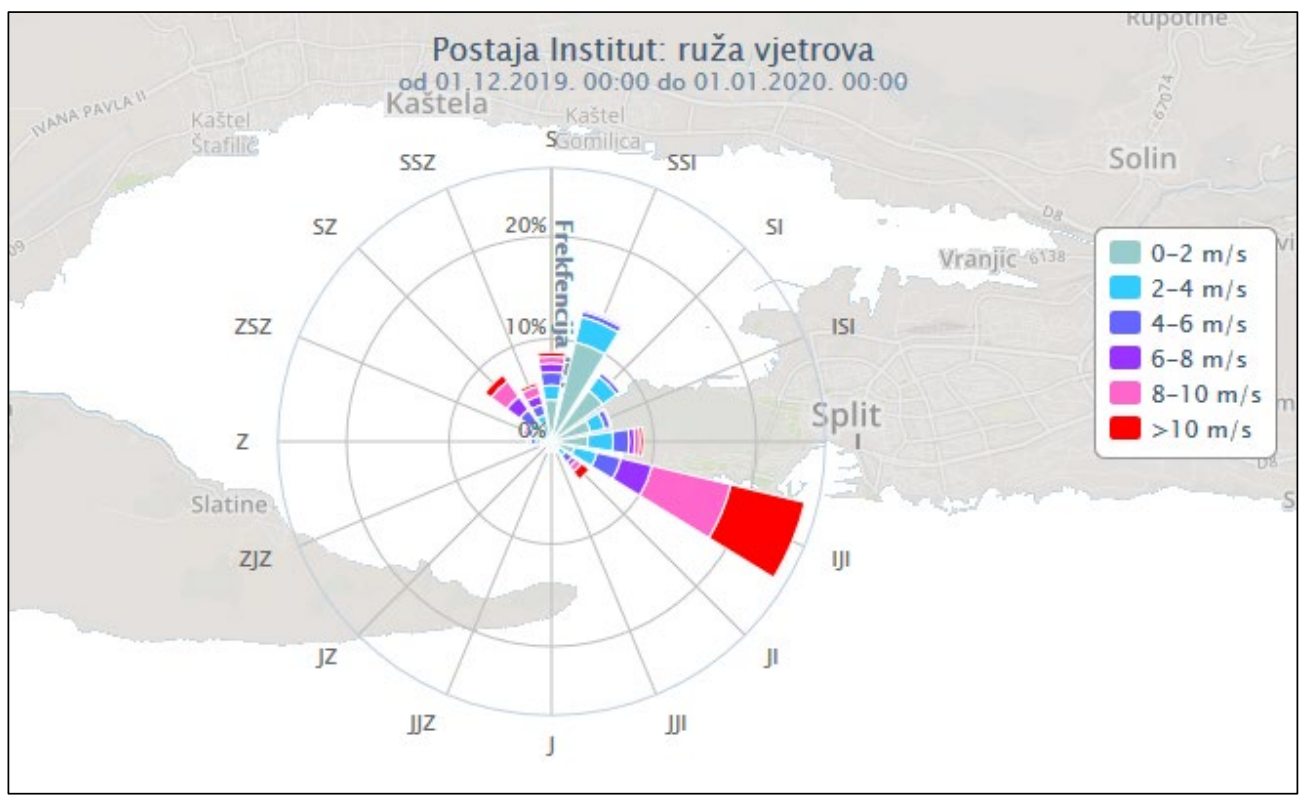

FIGURE 3

WIND SPEED - AREA OF SPLIT

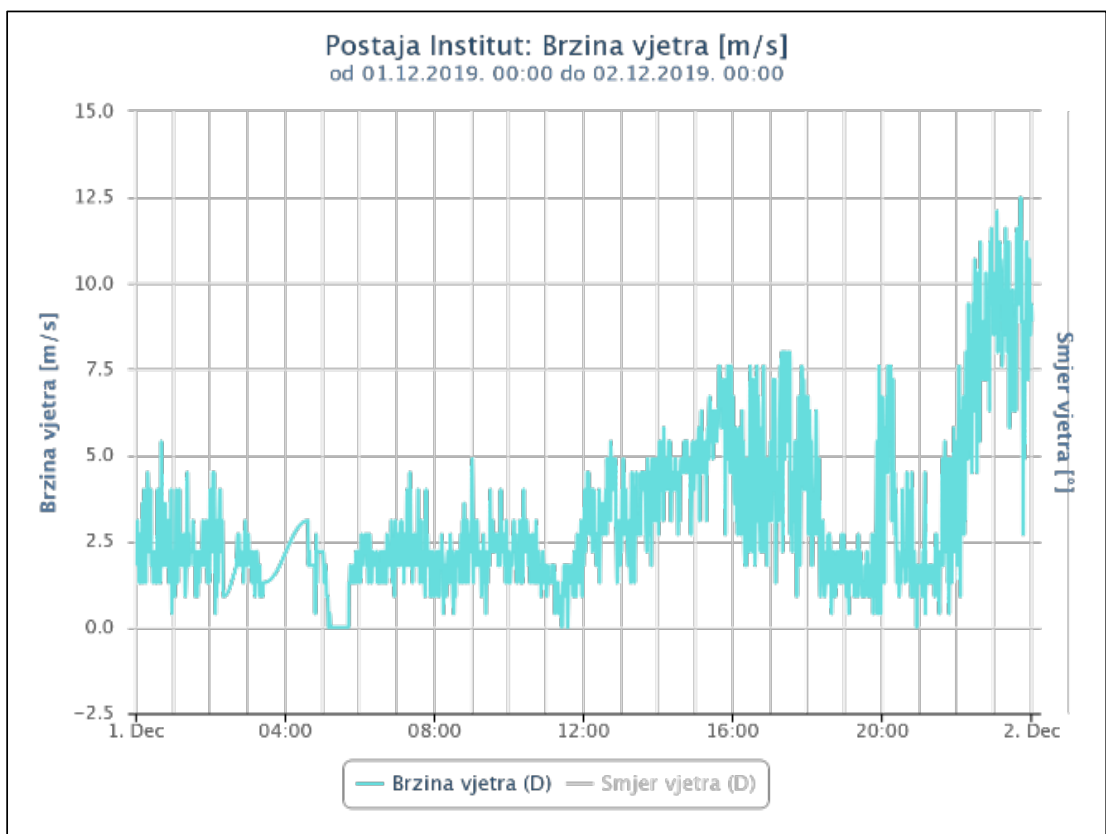

Graphical curves of selected wind turbine for the power and produced electrical energy in relation to the wind speed are shown in Figure 4 and 5. 
FIGURE 4

\section{POWER VS. WIND SPEED CURVE FOR WIND TURBINE}

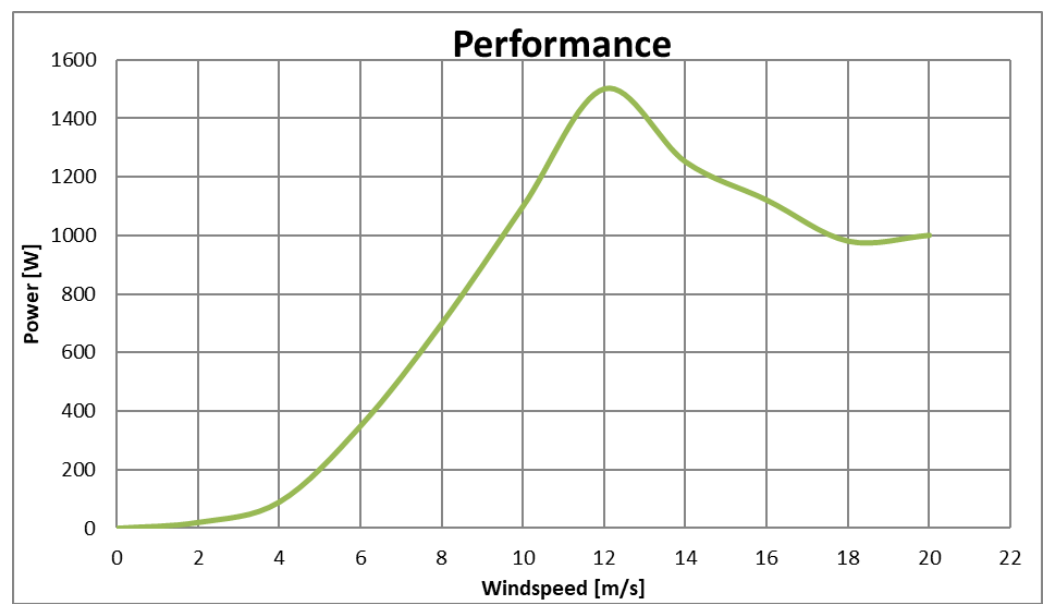

FIGURE 5

ANNUAL ENERGY PRODUCED VS. WIND SPEED CURVE

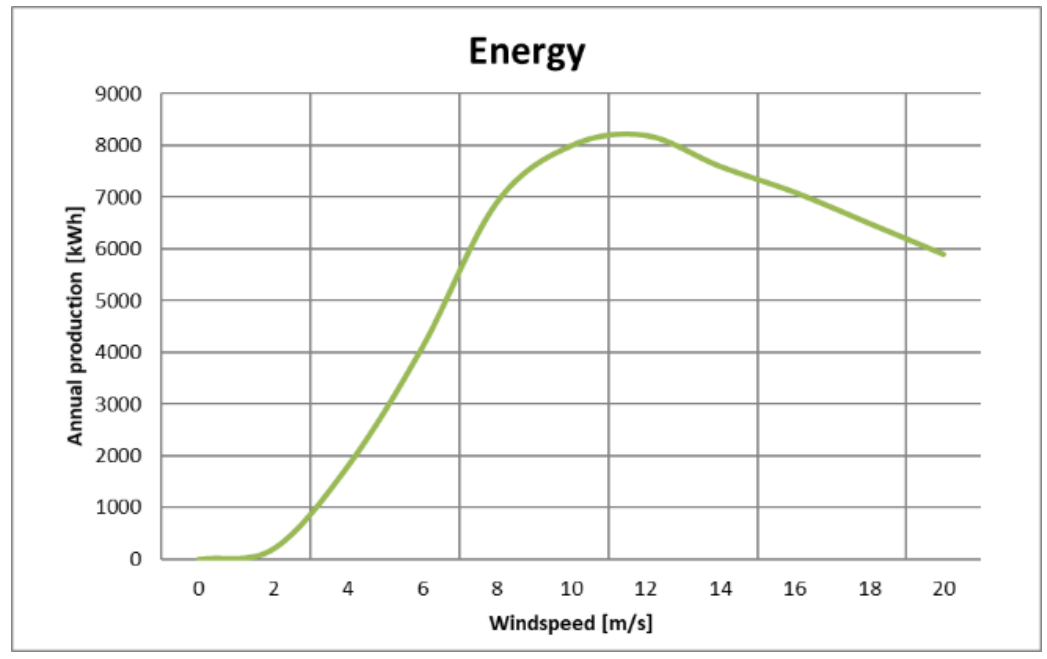

According to the shown curves and analysis of wind data is determined the potential of electrical energy production. Bplanner software tool from Bornay was used to calculate an estimation of wind speed and electrical energy production during one-year period at monthly intervals, as shown in Table 2 (Bornay Bplanner Web site, 2020). 
TABLE 2

AVERAGE WIND SPEED, PRODUCED AND CONSUMED ELECTRICAL ENERGY

\begin{tabular}{|l|c|c|c|}
\hline Month & Windspeed $[\mathrm{m} / \mathrm{s}]$ & Wind production $[\mathrm{kWh} /$ day $]$ & Consumption $[\mathrm{kWh} /$ day $]$ \\
\hline January & 2,88 & 1,62 & 0,63 \\
\hline February & 3,1 & 1,99 & 0,63 \\
\hline March & 2,97 & 1,62 & 0,63 \\
\hline April & 2,98 & 1,62 & 0,63 \\
\hline May & 2,5 & 1,01 & 0,63 \\
\hline June & 2,46 & 1,01 & 0,63 \\
\hline July & 2,42 & 1,01 & 0,63 \\
\hline August & 2,45 & 1,01 & 0,63 \\
\hline September & 2,41 & 1,01 & 0,63 \\
\hline October & 2,72 & 1,29 & 0,63 \\
\hline November & 2,81 & 1,62 & 0,63 \\
\hline December & 3,01 & 1,99 & 0,63 \\
\hline
\end{tabular}

The ratio of produced and consumed electrical energy chart can be seen in Figure 6. Based on these data, the wind turbine and other components of the system are dimensioned.

FIGURE 6

CHART OF PRODUCED AND CONSUMED ELECTRICAL ENERGY

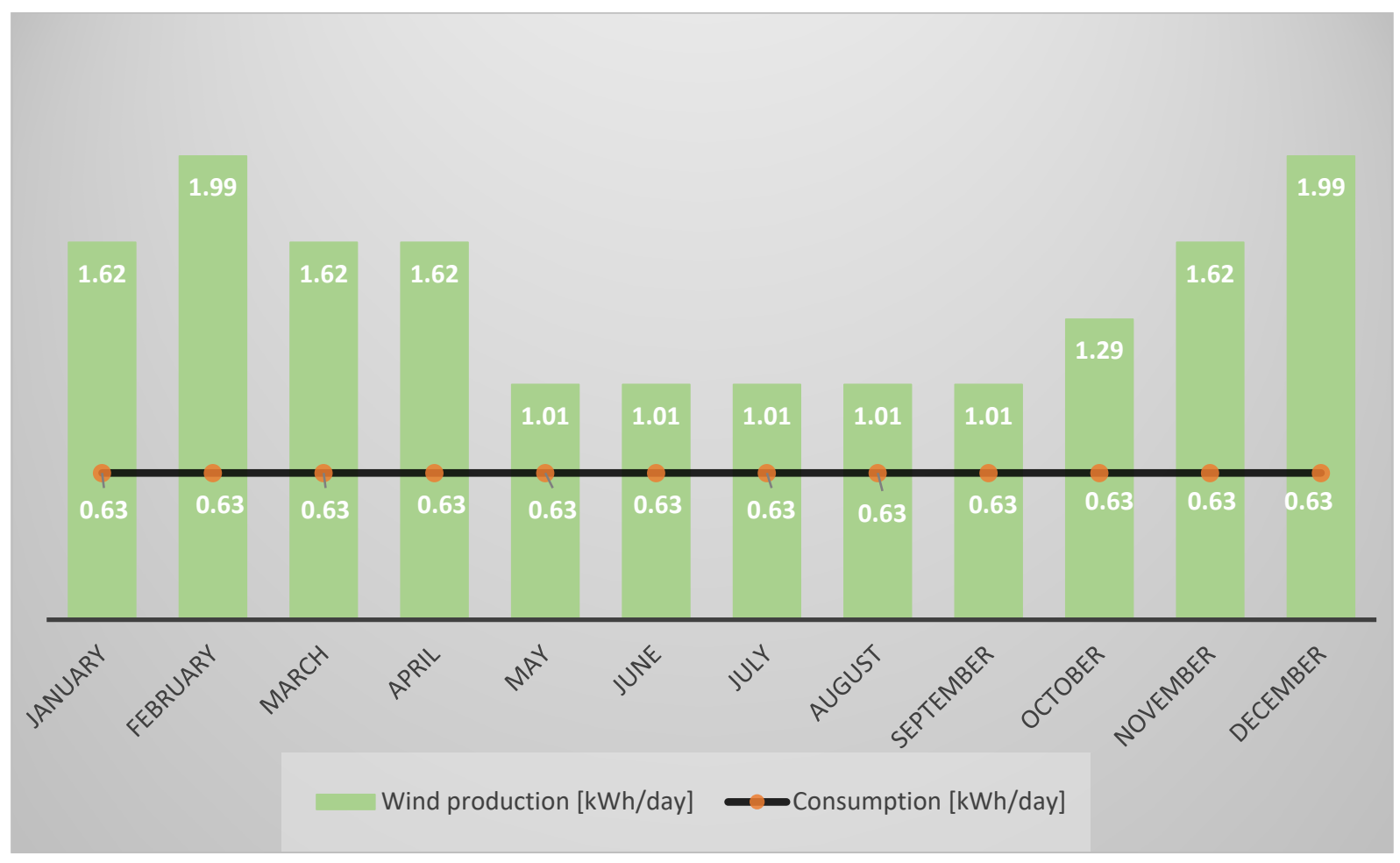

The wind turbine, as a basic component of the system, is dimensioned so that according to location's wind potential produces an adequate amount of electrical energy. The unit is controlled via a MPPT controller. In our case, the function of the controller is also to optimize the charging of the batteries. Batteries are used as additional storage of energy in order to make the system independent of the power 
grid. With fully charged batteries, system has autonomy of five days with the possibility that, if there is not enough wind, the batteries can be recharged from power grid. This is provided by a bidirectional converter that can conduct energy in both directions. In the first case it works as a rectifier, while in the second it works as an inverter and supplies $230 \mathrm{~V}$ AC to consumers. Figure 7 shows the installation of wind turbine system with all the major system components (Bornay Web site, 2019).

FIGURE 7

INSTALLATION OF WIND TURBINE SYSTEM

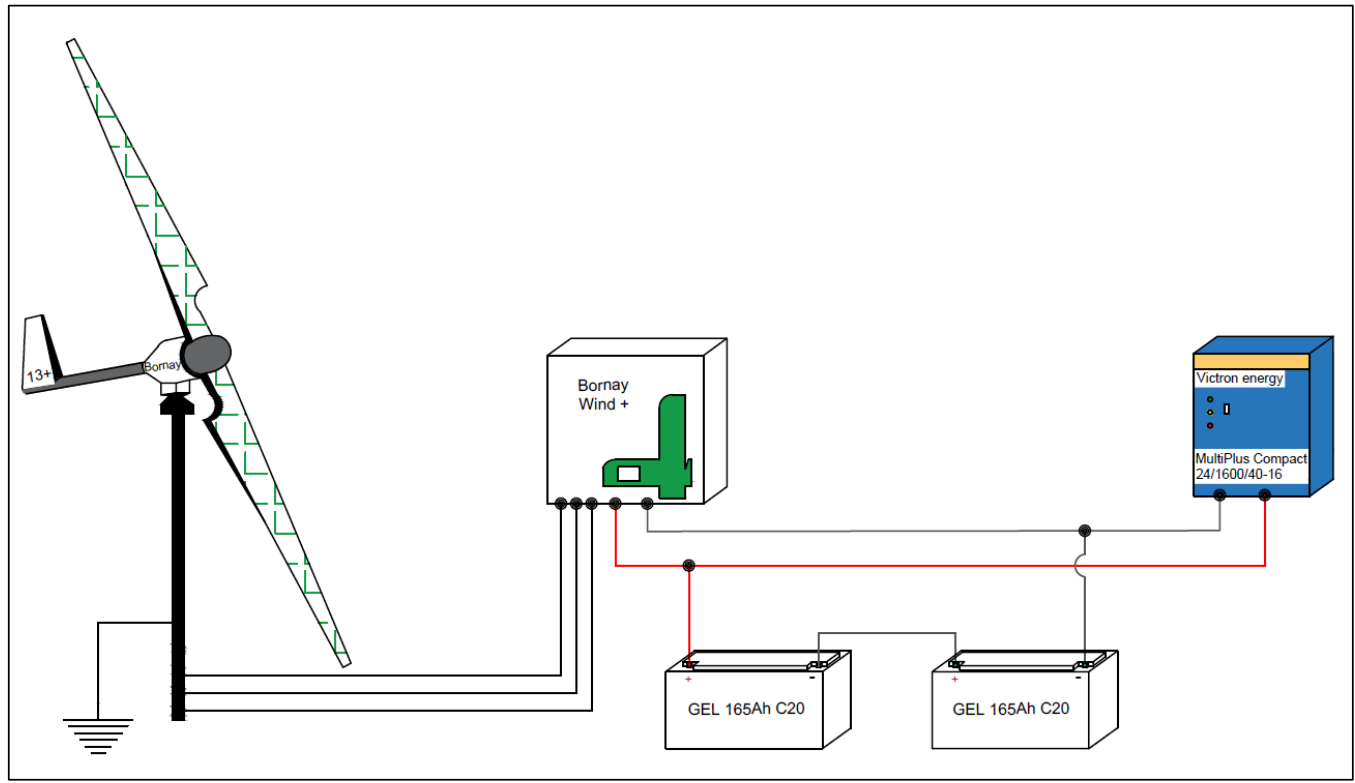

Detailed technical specifications of the components can be found in Table 3 (Bornay Wind13+, 2019; Bornay Wind+, 2019).

TABLE 3

TECHNICAL SPECIFICATIONS OF WIND TURBINE MAIN COMPONENTS

\begin{tabular}{|l|c|}
\hline \multicolumn{2}{|l|}{ Wind turbine } \\
\hline Nominal power & $1500 \mathrm{~W}$ \\
\hline Nominal voltage & $220 \mathrm{~V}$ \\
\hline Nominal RPM & 600 \\
\hline Alternator type & 2 \\
\hline Number of blades & $2,86 \mathrm{~m}$ \\
\hline Diameter & $2-30 \mathrm{~m} / \mathrm{s}$ \\
\hline Operation range & $3 \mathrm{~m} / \mathrm{s}$ \\
\hline Turn on & $12 \mathrm{~m} / \mathrm{s}$ \\
\hline Nominal power & $14 \mathrm{~m} / \mathrm{s}$ \\
\hline Automatic brake system & $60 \mathrm{~m} / \mathrm{s}$ \\
\hline Maximum & Wind $13+$ \\
\hline Model & \\
\hline
\end{tabular}




\begin{tabular}{|l|c|}
\hline \multicolumn{2}{|l|}{ Controller } \\
\hline Input voltage & $80-480 \mathrm{~V}$ \\
\hline Output voltage & $12 \mathrm{~V} / 24 \mathrm{~V} / 48 \mathrm{~V}$ \\
\hline Maximum power & $3000 \mathrm{~W}$ \\
\hline Maximum braking power & $5000 \mathrm{~W}$ \\
\hline Anemometer input & Yes \\
\hline Model & Wind $13+$ \\
\hline
\end{tabular}

\begin{tabular}{|l|c|}
\hline Batteries \\
\hline Voltage & $24 \mathrm{~V}$ \\
\hline Autonomy & 5 days \\
\hline Battery capacity & $165 \mathrm{Ah} \mathrm{C} 20$ \\
\hline Units & 2 \\
\hline Model & Victron $165 \mathrm{Ah} / 12 \mathrm{~V} \mathrm{GEL}$ \\
\hline
\end{tabular}

\begin{tabular}{|l|c|}
\hline \multicolumn{2}{|l|}{ Inverter } \\
\hline Input voltage & $24 \mathrm{~V}$ \\
\hline Output voltage & $230 \mathrm{~V}$ \\
\hline Frequency & $50 \mathrm{~Hz}$ \\
\hline Inverter power 25 C & $1300 \mathrm{~W}$ \\
\hline Charger & Yes (16 A) \\
\hline Model & $\begin{array}{c}\text { Phoenix MultiPlus C } \\
24 / 1600 / 40-16\end{array}$ \\
\hline
\end{tabular}

\section{WIND TURBINE MONITORING AND CONTROL}

In order to effectively manage the system for the scope of laboratory exercises, the system can be controlled locally through the control cabinet and remotely using the PLC. Energy flows through the system can be fully controlled and measured. Figure 8 shows wind turbine wiring diagram with all major components. The bidirectional converter is connected to the power grid with the contactor KM1. Contactor KM2 enables switching on and off $230 \mathrm{~V}$ AC consumers connected to the inverter. The MPPT controller, in addition to charging the batteries, is also used to brake the wind turbine by resistor or short circuit and thus to disconnect power from the generator.

For the purpose of analysing the state of the system, measurements are made at all relevant points. The measuring points and measuring units are shown in Figure 8. All measured data can be read on the control cabinet's measuring instruments and on the computer using the SCADA system. The status of the system can also be monitored through the Internet, i.e. online. 
FIGURE 8

WIND TURBINE WIRING DIAGRAM

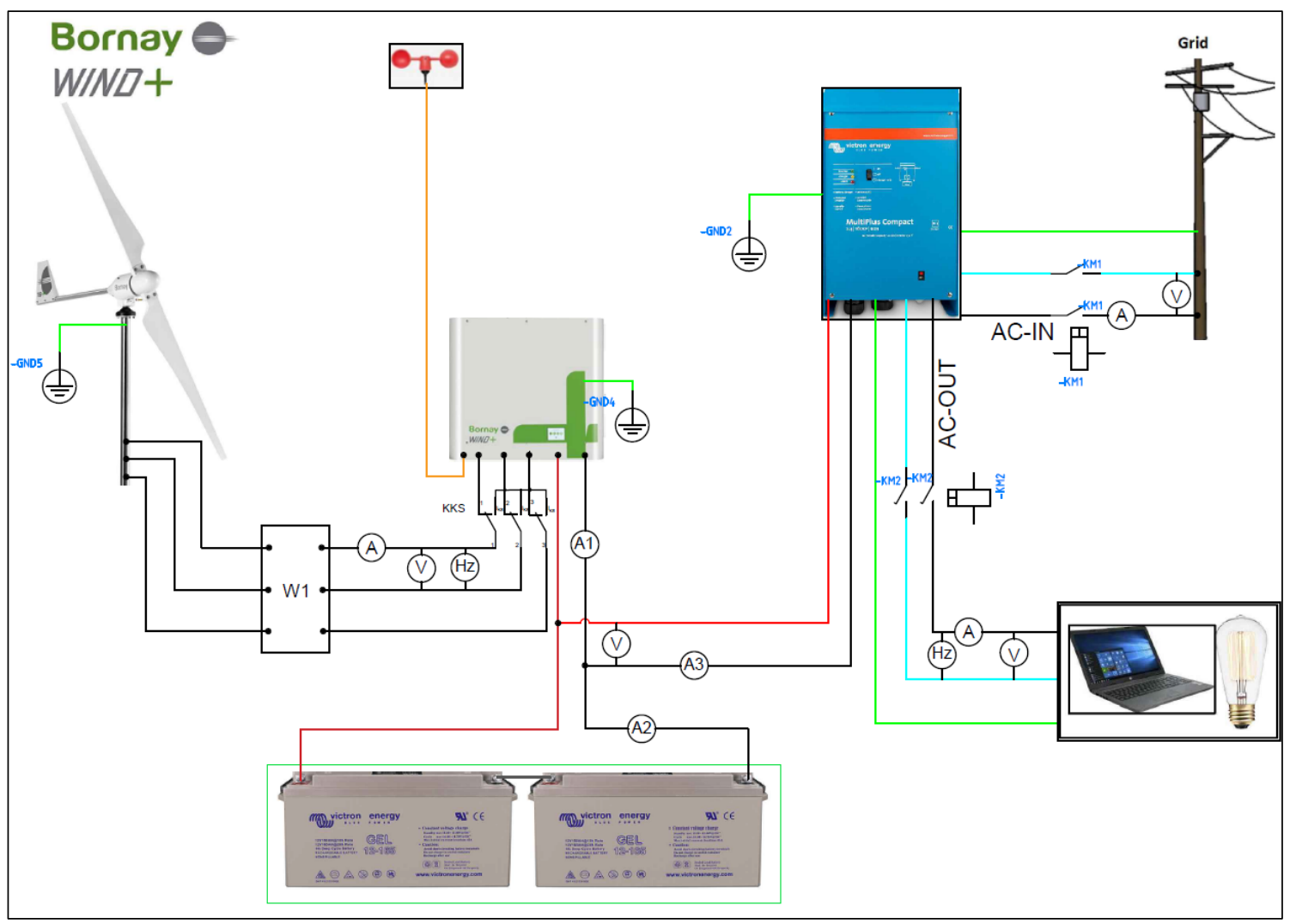

Figure 9 shows wind turbine wiring diagram for the control part. The control is performed with relays and associated contactors. As shown in Figure 9, relays KA1 and KA2 control the contactors KM1 (ACInput) and KM2 (AC-Output), and the relay KA4 controls the brake of wind turbine. In order to prevent the brake from being accidentally actuated, an additional brake permit must be issued. This is done by pressing the permit pushbutton that activates relay KA5, which is a precondition for engaging the brake. Once the braking has been activated, the KA5 relay is reset and the whole procedure must be repeated for new braking.

Local control of the system is managed through $\mathrm{S}_{\mathrm{x}}$ pushbuttons. By pressing the pushbuttons with NO contact (normally open) appropriate relays and contactors are activated and certain control lines are switched on, e.g. AC-Input, AC-Output, Brake-ON, etc. Pushbuttons with NC contact (normally closed) are used for theirs' disconnection.

Remote control is implemented via digital outputs on the PLC and SCADA system. Through digital outputs, the voltage is applied to the desired relays. The control mode selection is made on control panel with SA2 switch, which supplies 24V DC voltage to the $S_{x}$ pushbuttons or the PLC through emergency stop button (ES). By pressing emergency stop button user can switch off entire system in case of hazardous situation. 
FIGURE 9

WIND TURBINE WIRING DIAGRAM FOR THE CONTROL PART

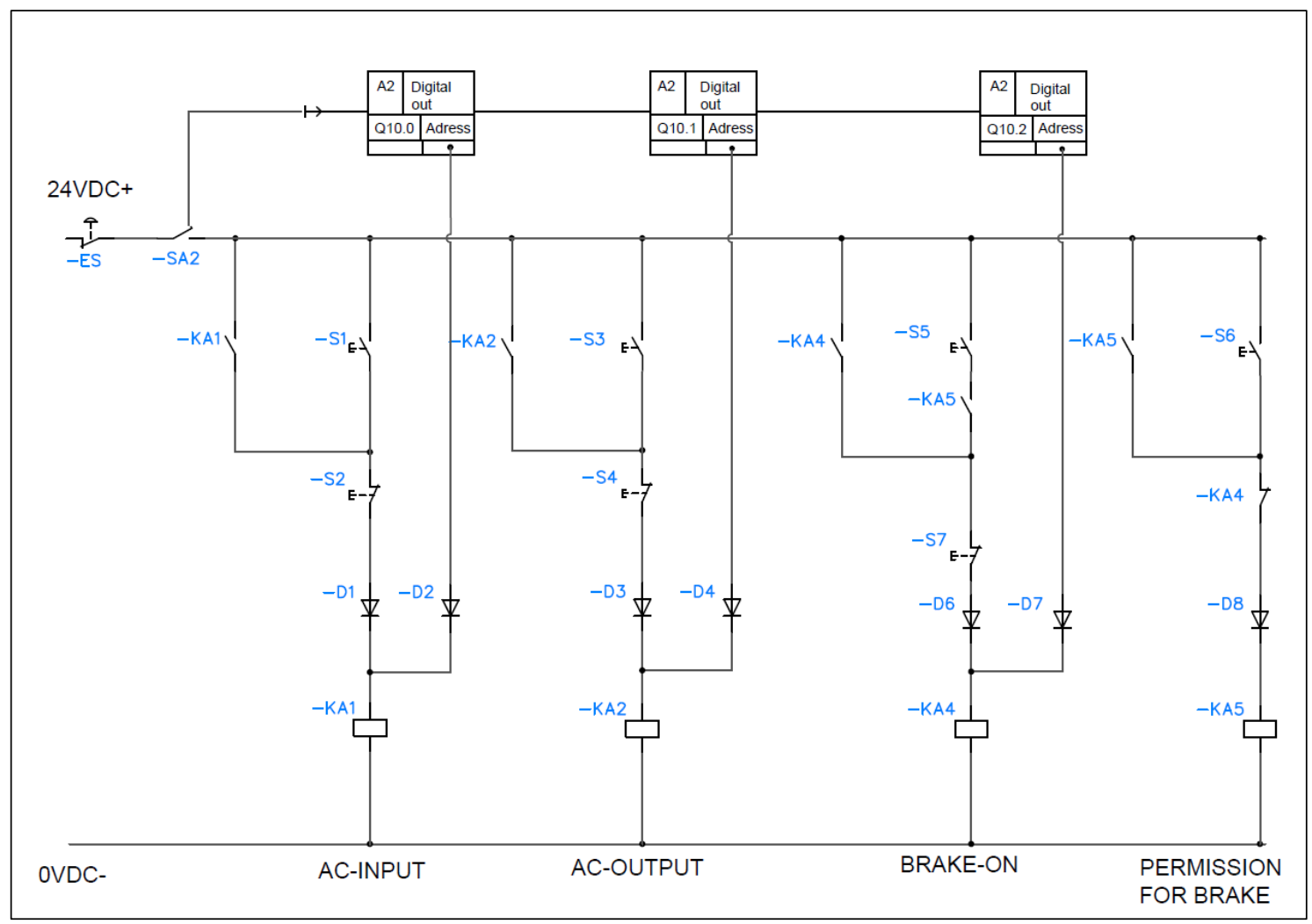

Remote control is performed using Siemens S7-1200 PLC with CPU version 1214C which has the possibility of additional connection of up to 8 signal modules and 3 communication modules.

PLC management and the SCADA system are implemented using the Siemens TIA Portal v15 platform in which these two functions are integrated, which simplifies the creation of the SCADA application itself. In addition to displaying the measuring data, SCADA also allows remote control of the system via the appropriate buttons. In the upper left of the SCADA, the user can see general system status information such as control mode, PLC power supply status, battery status, emergency stop status or system error status. Errors are recorded through a list of alarms that the user can see with the date and time of their occurrence. All the errors need to be acknowledged by the user.

Communication between the PLC and SCADA is made over the LAN to allow communication with other parts of the energy system. Wind turbine SCADA graphical interface example is shown in Figure 10. 
FIGURE 10

WIND TURBINE SCADA

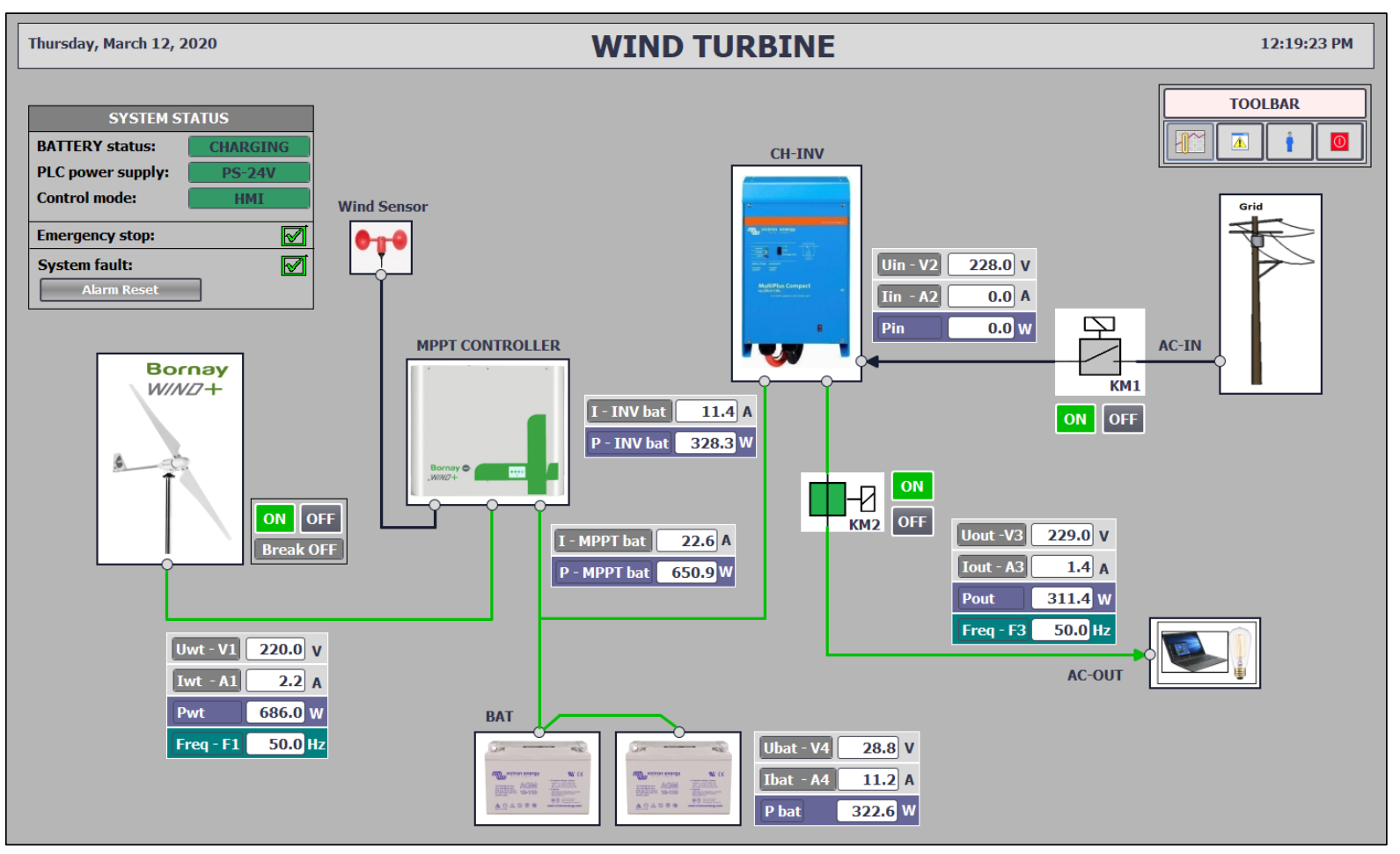

\section{APPLICATION OF WIND TURBINE IN EDUCATION}

The presented wind turbine system is primarily intended for the education of electrical engineering students. Through laboratory exercises students will analyze and study the operation of entire system as well as the individual components of the system. Particular emphasis is given to the conversion of wind energy, as a renewable energy source, into electrical energy and to efficiency of wind turbine. Students will also be introduced to the methods of control in electrical systems and to the preparation and understanding of technical documentation.

With the further development of the power engineering laboratory, it is foreseen that the wind turbine would be integrated into the internal power system, which would consist of a photovoltaic system, a synchronous generator driven by a controllable asynchronous motor and a consumer field. The intention is that all sources can be synchronized and integrated into the system to be able to deliver required power to the consumer field. Management would be also possible locally or remotely via the SCADA system. Figure 11 shows a graphical interface of the SCADA power system with the visualized power flows between individual sources and consumer field. 


\section{SCADA FOR ELECTRICAL POWER SYSTEM}

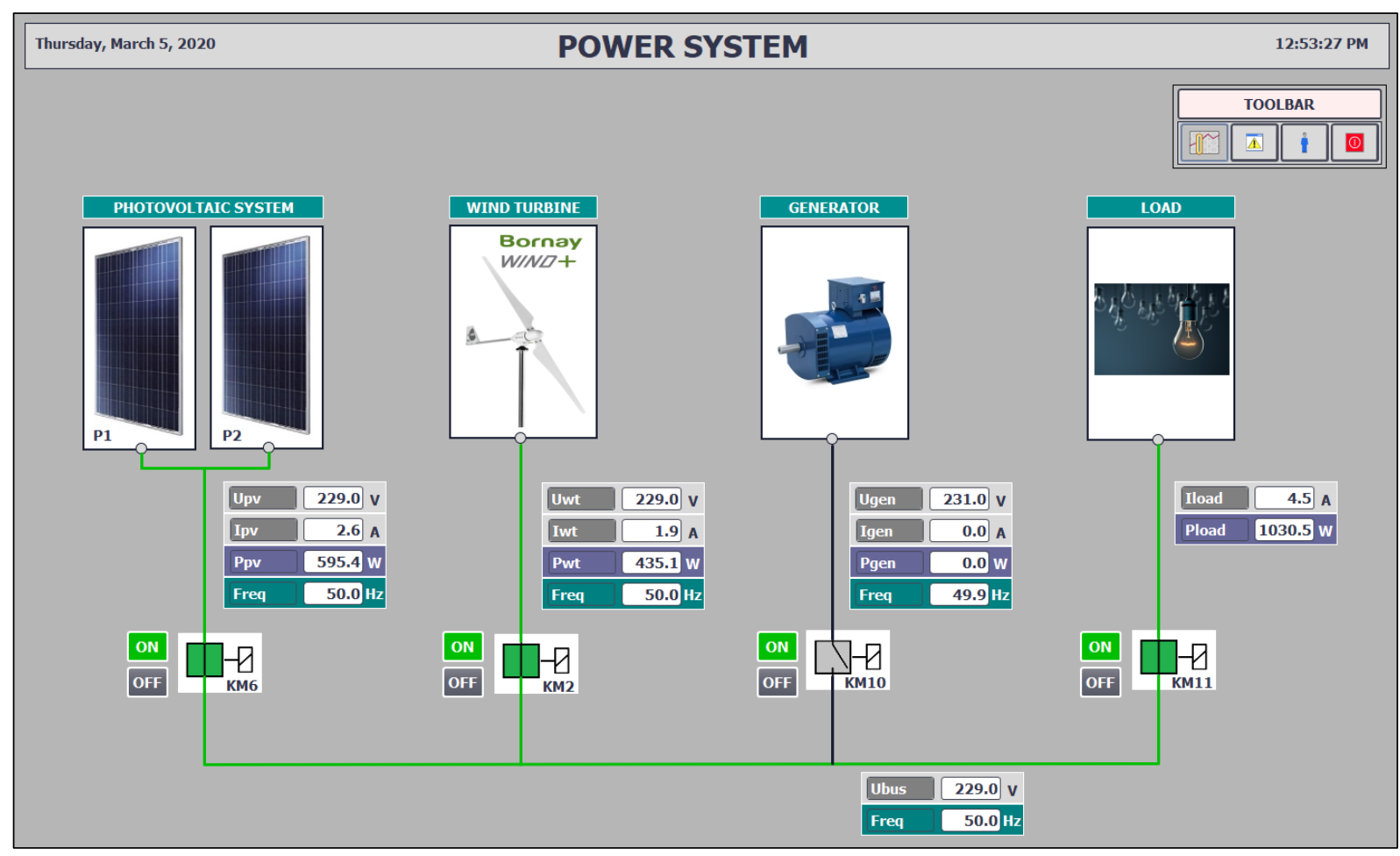

\section{CONCLUSION}

The paper describes a sequence of actions in the design of a wind turbine system, from determining the wind potential for a given location, estimating the consumption and production of electrical energy, dimensioning the system elements to designing the control and monitoring. The intention was to design a system that would allow students to become more familiar with: the use of wind energy, the principle of operation of individual components and entire system, and the management and monitoring of the system. The wind turbine system is intended to be part of a future internal power system that will be a hybrid type and will integrate solar energy, wind energy and energy produced by a synchronous generator driven by a controllable asynchronous motor. Considering that there is an increasing need for the use of renewable energy sources, we have the opinion that such an equipped laboratory at the University Department of Professional Studies at the University of Split will make a significant contribution to the education of future electrical engineers. 


\section{REFERENCES}

Bornay Bplanner Website. (n.d.). Retrieved February 11, 2020, from https://www.bornay.com/en/bplanner

Bornay Website. (n.d.). Retrieved November 4, 2019, from https://www.bornay.com/en/products/smallwind-turbines/wind-plus-swt.print

Bornay, Wind+ MPPT Charge Controller Manual Version 2.0 - 01.19. (n.d.). Retrieved November 4, 2019, from https://www.bornay.com/media/download/2692

Bornay, Wind13+ Manual Version 1.5 - 07.17. (n.d.). Retrieved November 4, 2019, from https://www.bornay.com/media/download/1847

Institute of Oceanography and Fisheries Website. (n.d.). Retrieved December 1, 2019, from https://acta.izor.hr/wp/en/

Karadža, N., Bačan, A., Horváth, L., \& Knežević, S. (2009). Mali vjetroagregati i fotonaponski moduli za autonomne aplikacije na otocima Primorsko-goranske županije. Zagreb, Hrvatska: Energetski institut Hrvoje Požar.

Manwell, J.F., McGowan, J.G., \& Rogers, A.L. (2009). Wind Energy Explained: Theory, Design and Application 2nd. Chichester. United Kingdom: John Wiley \& Sons, Ltd.

Žarko, D., Stipetić, S., Sumina, D., \& Bariša, T. (2017). Generatori sa stalnim magnetima za vjetroelektrane. 13th HRO CIGRE Session, pp. A1-146. 